\title{
Article
}

\section{Syntactic co-activation in natural reading}

Vaughan-Evans, Awel, Liversedge, Simon Paul, Fitzsimmons, Gemma and Jones, Manon W.

Available at http://clok.uclan.ac.uk/35238/

Vaughan-Evans, Awel, Liversedge, Simon Paul ORCID: 0000-0002-8579-8546, Fitzsimmons, Gemma and Jones, Manon W. (2020) Syntactic co-activation in natural reading. Visual Cognition, 28 (10). pp. 541-556. ISSN 1350-6285

It is advisable to refer to the publisher's version if you intend to cite from the work. http://dx.doi.org/10.1080/13506285.2020.1841866

For more information about UCLan's research in this area go to http://www.uclan.ac.uk/researchgroups/ and search for <name of research Group>.

For information about Research generally at UCLan please go to http://www.uclan.ac.uk/research/

All outputs in CLoK are protected by Intellectual Property Rights law, including Copyright law. Copyright, IPR and Moral Rights for the works on this site are retained by the individual authors and/or other copyright owners. Terms and conditions for use of this material are defined in the policies page.

\section{CLoK}

Central Lancashire online Knowledge www.clok.uclan.ac.uk

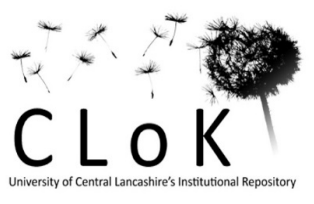




\section{Syntactic co-activation in natural reading}

Awel Vaughan-Evans ${ }^{\mathrm{a}^{*}}$, Simon P. Liversedge ${ }^{\mathrm{b}}$, Gemma Fitzsimmons ${ }^{\mathrm{c}}$ and Manon W. Jones ${ }^{\mathrm{a}}$

${ }^{a}$ School of Psychology, Bangor University, Wales, UK; ${ }^{b}$ School of Psychology,

University of Central Lancashire, England, UK; ${ }^{c}$ University of Southampton, England, $U K$

*corresponding author

Dr Awel Vaughan-Evans

School of Psychology

Bangor University

Gwynedd LL57 2AS

United Kingdom

Telephone +44 (0) 1248388058

Email: a.vaughan-evans@bangor.ac.uk 


\section{Syntactic co-activation in natural reading}

Recent evidence suggests that bilingual individuals co-activate the syntactic rules of both languages. However, the extent to which syntactic co-activation occurs during natural reading is currently unknown. Here, we measured the eye movements of Welsh-English bilinguals as they read English sentences. We also tested a control group of English monolinguals. Target words were manipulated to create nonwords that were consistent or inconsistent with the rules of Welsh soft mutation (a morphosyntactic process that alters the initial consonant of words). Nonwords were only visible in parafoveal preview, and a direct fixation triggered the presentation of the normal English word. Linear mixed effects analyses revealed a robust parafoveal preview benefit for identity previews (television) compared with mutated (delevision) and aberrant previews (belevision), and a parafoveal-on-foveal effect in our bilingual, but not our monolingual, sample. Bilingual readers' sentence reanalysis was affected by the implicit Welsh mutation, but only in contexts that would elicit a mutation in Welsh. Our findings suggest that morphosyntactic rules are co-activated during natural reading, however further investigations are needed to evaluate the robustness of this effect.

Keywords: bilingualism; syntactic co-activation; morphosyntax; eye tracking; boundary paradigm 


\section{Introduction}

A key aim in psycholinguistic research is to elucidate the functional organisation of languages in bilinguals, with debate centring on whether each language is represented and accessed separately, or whether the two languages are simultaneously active. Specifically, during comprehension or production, do bilinguals only activate the representations of the language currently being used? Or, are properties of the apparently silent (non-operational) language co-activated? With regards to lexical processing, the debate on co-activation (or selective vs. nonselective access) has generated a substantial amount of research (see Lauro \& Schwartz, 2017, for a recent review), and whilst early research favoured a language selective account (e.g. Gerard \& Scarborough, 1989; Soares \& Grosjean, 1984), the weight of evidence currently falls in favour of language nonselective access (e.g., Duyck, 2005; Jared \& Kroll, 2001; Lemhöfer \& Dijkstra, 2004; Thierry \& Wu, 2007; Van Assche, Duyck, Hartsuiker \& Diependaele, 2009; see Dijkstra \& Van Heuven, 1998; van Heuven, Dijkstra \& Grainger, 1998, for a model of bilingual lexical access that can account for both language selective and language nonselective findings).

The intense focus on lexical access in bilinguals stands in stark contrast with the relatively few studies that have investigated whether syntactic representations are language selective or nonselective in bilinguals. Current evidence suggests that bilinguals' syntactic systems are co-active: Cross-linguistic syntactic priming studies show that bilinguals are more likely to produce a specific grammatical construction having been recently exposed to the same construction, irrespective of whether the prime language is the same or different from the response language (e.g., Hartsuiker, Pickering \& Veltkamp, 2004). Interactivity between language systems is also curtailed as the syntactic similarity between languages decreases (Bernolet, Hartsuiker \& Pickering, 2007; see Hartsuiker \& Pickering, 2008, for a review). Other moderating 
factors include language proficiency (Bernolet, Hartsuiker \& Pickering, 2013;

Hartsuiker \& Bernolet, 2016; Hopp, 2017; see Bernolet \& Hartsuiker, 2018 for a recent review), immersion (Morales, Paolieri, Cubelli \& Bajo, 2014), exposure (Kaushanskaya \& Smith, 2016; Whitford \& Titone, 2016), context (Mercier, Pivneva \& Titone, 2015), and verbal fluency (Sanoudaki \& Thierry, 2015). However, recent data suggest that syntactic co-activation can also occur when syntactic structures differ between languages (Sanoudaki \& Thierry, 2014), and when the co-active rules are completely aberrant in the language currently being used, as in the case of soft mutation (VaughanEvans, Kuipers, Thierry \& Jones, 2014). Soft mutation is a morphosyntactic process that alters the initial consonants of Welsh words when placed in specific syntactic contexts (Ball \& Müller, 1992; Harlow, 1989). That is, changes in word phonology (and orthography) are dependent on the preceding syntactic context. Soft mutation is a highly complex rule set, and includes 26 distinct rules in which stops, liquids, and the nasal $/ \mathrm{m} /$ undergo a process of lenition $(\mathrm{p} \rightarrow \mathrm{b}, \mathrm{t} \rightarrow \mathrm{d}, \mathrm{k} \rightarrow \mathrm{g}, \mathrm{b} \rightarrow \mathrm{v}, \mathrm{d} \rightarrow$ d, $\mathrm{g} \rightarrow \varnothing, \mathrm{l} \rightarrow \mathrm{l}, \mathrm{r} \rightarrow \mathrm{r}, \mathrm{m} \rightarrow \mathrm{v}$; Thomas \& Gathercole, 2007). For example, the feminine Welsh noun cannwyll-candle - mutates after the definite article $y$-the; y gannwyll-the candle, whereas the masculine noun teledu - television does not: $y$ teledu - the television. Furthermore, the gender neutral pronoun ei (his/her/its) always elicits a mutation, but the type of mutation that should occur is determined by the antecedent of the sentence; a soft mutation only occurs when the pronoun refers to a masculine antecedent. Thus, certain sentence structures could, potentially, prime Welsh readers/listeners to expect a mutation before they encounter the mutation itself. We note that these examples are used simply to illustrate the complexity of the rule set and are by no means comprehensive (see Ball \& Müller, 1992, for a thorough account of Welsh mutations). In Vaughan-Evans et al.’s ERP study, Welsh-English bilinguals read English sentences 
ending in nonwords that were either 'mutated' according to a morphosyntactic rule of Welsh (e.g., prince $\rightarrow$ brince) or in an 'aberrant' form, which would never occur in Welsh (e.g., prince $\rightarrow$ grince). Results showed that English nonwords mutated according to Welsh rules were processed with greater ease than aberrant nonwords, but crucially, only when presented in sentence contexts that would elicit a mutation in Welsh. These findings contribute to an emerging picture of a fully interactive, nonselective syntactic system.

Online measures afford a window into bilinguals' representation of syntax that is arguably more sensitive than traditional behavioural measures, in which explicit presentation of both languages occurs (see Grosjean, 1998, for a discussion on the influence of bilingual contexts on language co-activation). However, Vaughan-Evans et al.'s study used explicit presentation of pseudo-nonwords, which has been found to influence the extent to which co-activation occurs. For example, Soares \& Grosjean (1984) demonstrated that presentation of a nonword automatically triggers lexical coactivation in bilingual participants, irrespective of whether the language context is monolingual or bilingual. Vaughan-Evans et al.'s explicit presentation of nonwords may therefore have maximised the possibility for syntactic co-activation. In order to assess the extent of bilingual syntactic co-activation under sentence reading conditions approximating a more 'normal' monolingual setting, we devised a task in which variations of mutated nonwords were presented only implicitly.

\section{The Current Study}

In this study, we examined whether bilingual syntactic co-activation occurs in natural silent sentence reading, under highly conservative conditions. Specifically, whether Welsh-English bilinguals reading English sentences, including explicit 
processing of an English target, nevertheless simultaneously activate the morphosyntactic rules of Welsh. In this eye-tracking experiment, previews of manipulated target words were presented in the parafovea (an area 2-5 degrees of visual angle from the centre of foveal vision) via the boundary paradigm (Rayner, 1975) but appeared as normal English words upon fixation. As such, previews only appeared prior to direct fixation.

Our experimental conditions included English target words that were manipulated according to the rules of Welsh soft mutation (cf., Vaughan-Evans et al., 2014). The initial consonants of English target words were therefore manipulated in a way that adhered to soft mutation rules (e.g., television $\rightarrow$ delevision: the initial consonant $t$ always mutates to $d$ ) or were aberrant with respect to soft mutation rules (e.g., television $\rightarrow$ belevision: the initial consonant $t$ never mutates to $b$ ). Parafoveal previews thus consisted of a) identity previews (e.g., television), b) mutated previews (e.g. delevision) or c) aberrant previews (e.g., belevision). Furthermore, the syntactic context of experimental sentences was manipulated such that they would, or would not, elicit a mutation in Welsh. Importantly, the syntactic context was manipulated via a single change of the pre-target word (e.g., from the personal pronoun 'his' to the definite article 'the'; note that this is only one example, and that a variety of mutation triggers were used in the experiment).

We now turn to the hypotheses, which all relate to the target word. First, we predicted that trials in which the target remained identical between preview and fixation would elicit a preview benefit, consistent with previous studies implementing a boundary paradigm (see Rayner, 2009, for a review). We therefore predicted shorter fixation durations on the target word for identity preview trials (television) compared with the nonword preview trials (delevision; belevision). We expected this general 
finding irrespective of whether the target occurred in a mutation or non-mutation sentence context, and irrespective of the language profile of the participants (WelshEnglish bilinguals or English monolinguals).

However, for trials in which the target was mutated between preview and fixation, inconsistencies in the current literature make predictions less straightforward: Vaughan-Evans et al., (2014) suggest that activation of Welsh morphosyntactic rules facilitates reading, suggesting that mutated previews should yield shorter reading times. However, in bilingual sentence reading studies, implicit activation of the non-target language typically results in prolonged first fixation durations, gaze durations, and total reading times (e.g., Frenck-Mestre \& Pynte, 1997; Libben \& Titone, 2009; Hopp, 2017); effects typically attributed to inhibition arising from a temporary conflict in information processing between the two languages. We suggest that such seemingly disparate findings can be reconciled by considering stages of processing across fixations: In preview, the soft mutation rule allows participants to predict a mutation, disrupting (or at least imposing a processing cost upon) language-appropriate syntactic processing. Thus, mutated parafoveal previews of the target are partially expected, leading to ease of processing before explicit processing takes place. However, upon fixation of the target - at which point it reverts to its non-mutated state - the Welsh rule is no longer salient, leading to a temporary conflict between the two syntactic systems. As such, we predicted that mutated nonwords would be maximally disruptive to reading in mutation context sentences, since it was the condition most likely to elicit activation of the soft mutation rule in Welsh. This was expected to manifest in an interaction effect, in which mutation preview conditions yielded disproportionately longer reading times compared with identity preview conditions, but only in mutation context sentences. We did not expect an analogous effect for aberrant nonwords (control items), 
and we did not expect a similar interaction in our control group of English monolinguals.

In previous studies, bilingual syntactic co-activation has typically been interpreted from a lexicalist perspective (in which activation of a syntactic representation occurs via activation of a translation equivalent; Hatzidaki, Branigan \& Pickering, 2011). However, more recent findings suggest that co-activation may occur via the application of abstract syntactic rules (e.g., Sanoudaki \& Thierry, 2014; Vaughan-Evans et al., 2014). In order to test the mechanism by which syntactic coactivation occurs during natural reading, we manipulated phonological overlap between languages. Half of the English target words shared an initial consonant with their Welsh translation equivalents (e.g. cannwyll-candle; overlap condition), and half did not (e.g. crempog-pancake; no overlap condition; see Table 1). If syntactic co-activation occurs as a result of cross-linguistic lexical associations, we anticipated that our bilingual participants would show the effects described above in 'overlap' trials but not in 'no overlap' trials. If co-activation occurs via the application of abstract syntactic rules, we hypothesised a similar pattern of results for both 'overlap' and 'no overlap' target words.

Moreover, different eye-tracking measures enabled us to investigate the time course of any such effects. Specifically, we were able to assess whether these effects were associated with the earliest stages of lexical processing during access of phonological information (in which case the effect of our linguistic manipulation should occur during first pass inspection of the target itself). Evidence of co-activation in these early measures would suggest that activation of the syntactic properties of the nonoperational language occurs immediately and automatically. Alternatively, the effects might be associated with re-analysis and integration of the lexical item with the 
sentential context (in which case the effect of our linguistic manipulation would be expected to appear in later reading time measures associated with second pass reading

of the target). Evidence of co-activation only in these later measures would suggest that activation of the syntactic properties of the non-operational language occurs later, possibly as a result of translation, or a post-lexical evaluative process.

[Table 1 near here]

\section{Methods and Materials}

\section{Participants}

Sixty-nine Welsh-English bilinguals participated in this study. Of this sample, eight participants were excluded due to poor performance on an offline production task measuring their knowledge of the Welsh soft mutation rule (test score $<65 \%$ ). A further two participants were removed, after stating that they detected the boundary-paradigm manipulation during the debriefing procedure. Finally, six participants were excluded due to self-reporting of a reading or uncorrected visual impairment. These participants were excluded before data processing and were not included in any analyses. Thus, 53 highly proficient bilingual participants ( 5 male, 48 female; Mean age $=21.1$ years; $S D=$ 5.5) were included in the final analysis for our bilingual sample, all of which selfreported that they had learnt English from an early age $(M=3.9$ years; $S D=2.7)$. A further 55 English monolingual participants were tested as a control group. Of this sample, three participants were excluded as they were proficient in another language, as assessed by a language history questionnaire. A further three participants were removed, after stating that they detected the boundary-paradigm manipulation during the debriefing procedure. These participants were excluded before data processing and were not included in any analyses. Thus, 49 proficient English monolinguals (19 male, 30 
female; Mean age $=21$ years; $S D=4.8$ ) were included in the final analysis for our monolingual sample. All participants possessed normal or corrected to normal vision. Ethical approval was obtained from Bangor University Psychology Ethics Committee, and all participants provided written consent.

\section{Apparatus}

An SR Research Eyelink 1000 eye-tracking system with a sampling rate of $1000 \mathrm{~Hz}$ was used to track participants' eye movements. Sentences were presented in black monospaced Courier font on a grey background. The font size was controlled such that, at a viewing distance of $70 \mathrm{~cm}, 1$ degree of visual angle $(1.22 \mathrm{~cm})$ was occupied by three characters. Sentences were presented on a single line on a CRT monitor with a refresh rate of $100 \mathrm{~Hz}$.

\section{Materials and design}

Ninety-six English target words were selected (forty-eight that did share an initial consonant with their Welsh translation equivalents, and forty-eight that did not). Target words were only selected if they started with a ' $\mathrm{P}$ ', ' $\mathrm{T}$ ', or ' $\mathrm{C}$ ', and if their translation equivalents started with a 'P', 'T', or 'C' (e.g., overlap condition: cannwyll -candle; no overlap condition: crempog - pancake). These consonants result in mutations that are phonologically and orthographically comparable in Welsh and English $(\mathrm{P} \rightarrow \mathrm{B} ; \mathrm{T} \rightarrow \mathrm{D}$; $\mathrm{C} \rightarrow \mathrm{G}$ ). Two sentence frames were then constructed for each target word, identical with the exception of the pre-target word: one frame would have required a soft mutation had it been presented in Welsh (henceforth referred to as 'mutation context'), and one would not have required a soft mutation had it been presented in Welsh (henceforth referred to as 'no mutation context'). Word frequencies were obtained from the English lexicon 
project (Balota et al., 2007) and reflect log transformed word frequencies from the Hyperspace Analogue to Language (HAL) norming study (Lund \& Burgess, 1996).

In order to ensure the comparability of our pre-target words, we conducted two independent ANOVAs with Overlap (overlap vs. no overlap) and Context (mutation context vs. no mutation context) as independent variables, and word length and word frequency as dependent variables. For pre-target words, word frequency did not differ significantly between conditions (Main effect of Overlap: $F(1,188)=0.96, p=.329$; Main effect of Context: $F(1,188)=2.39, p=.124$; Overlap*Context interaction: $F(1,188)=1.64, p=.202$ ) nor did word length (Main effect of Overlap: $F(1,188)=$ $0.26, p=.610$; Main effect of Context: $F(1,188)=3.21, p=.075$; Overlap*Context interaction: $F(1,188)=0.07, p=.798$; see Table 2$)$. In addition, independent samples $\mathrm{t}-$ tests revealed that target word frequency did not differ significantly between overlap conditions $(t(94)=1.81, p=.074)$ nor did target word length $(t(94)=0.89, p=.376$; see Table 3).

[Table 2 near here]

[Table 3 near here]

Our manipulated words were presented only in parafoveal preview, and comprised identity, mutated and aberrant previews, appearing in mutation and no mutation context sentences. Note that English target words were specifically selected to create nonwords in mutated and aberrant word conditions (e.g., the word park was excluded, since its mutated equivalent produces the real English word bark). Thus, our experiment comprised a 3 (word preview; identity, mutated, aberrant) x 2 (sentence context; mutation, no mutation) x 2 (overlap; overlap, no overlap) design. Six counterbalancing lists were created; each list included the 96 target items (48 'overlap' and 48 'no overlap'), with each item appearing in only one experimental condition. To clarify, each 
participant saw each target word only once, resulting in a total of 8 trials per condition. A Latin square counterbalancing procedure ensured that each item appeared only once in each counterbalancing list (corresponding to one experimental procedure). Each counterbalancing list included an equal number of trials from each experimental condition. The 96 experimental sentences were presented along with 72 filler items, 48 of which were part of a separate boundary paradigm study consisting of purely English sentences.

In a separate pre-test, the cloze probability of the target word, and plausibility of all test sentences was measured. Twenty monolingual English speakers were presented with fragments of the test sentences up to the target word, and were asked to provide a semantically and syntactically appropriate word to complete the sentences. Responses were given a score of 1 if the completions matched our experimental sentences, and all other answers received a score of 0 . If a target word was never generated, or was not the most predictable completion, it was removed from the stimulus list. For 'overlap' sentences, overall probability was low $(M=.41)$, and no difference was observed between mutation context sentences $(M=.41)$ and no mutation context sentences $(M=$ $.40 ; p=.824)$. For 'no overlap' sentences, overall probability was also low $(M=.30)$, and no difference was observed between mutation context sentences $(M=.29)$ and no mutation context sentences $(M=.31 ; p=.441)$. Participants were then presented with the actual test sentences, and were asked to rate them on a scale of 1 (not plausible at all) to 7 (very plausible). For overlap sentences, plausibility ratings were high overall $(M=6.73)$, and did not differ between conditions (mutation context sentences: $M=$ 6.75 ; no mutation context sentences: $M=6.71 ; p=.69$ ). Plausibility ratings were also high for 'no overlap' sentences $(M=6.58)$, and did not differ between conditions 
(mutation context sentences: $M=6.62$; no mutation context sentences: $M=6.53 ; p=$ $.14)$.

\section{Procedure}

During the experimental session, participants were seated in front of a desk-mounted eye tracker, with their forehead resting against a headrest. The headrest was positioned approximately $70 \mathrm{~cm}$ from the CRT monitor, and was used for stabilization purposes. Upon reading the task instructions, a brief three-point calibration procedure was initiated. During this procedure, an acceptance criterion of an average error below 0.3 degrees of visual angle was set. Once the calibration process was complete, participants were presented with ten practice trials. Each trial began with a drift correction in the form of a small circle, placed in the same position as the beginning of the first word of the experimental sentences. Once the participant fixated on the circle, the experimenter pressed a button, and the trial began. If participants did not fixate on the circle, or if the degree of error was greater than 0.35 , they were recalibrated. Participants were instructed to read for comprehension, and comprehension questions requiring yes/no responses were included after a third of all trials. To reduce fatigue, participants were instructed to take small breaks during the experiment (typically after reading 40 sentences). Participants were recalibrated after each break, and as such, each participant was recalibrated at least four times during the experiment (thus reducing the chance of drift). Upon reading half of the experimental sentences, participants were asked to complete a language history questionnaire, which comprised questions relating to language acquisition, proficiency, and language use, and was used to ensure the comparability of the language profiles of our participants. This questionnaire also collected demographic information which was used to exclude some participants (see 
participants section). At the end of the testing session, participants were asked whether they noticed anything in particular about the sentences. They were then prompted and asked whether they noticed any changes when reading the sentences. If participants responded that they had noticed a change, they were asked to describe what they had noticed, and asked to state approximately how many times they had detected the change. If participants detected a boundary change manipulation five times or more, their data was removed prior to analysis.

\section{Post-tests}

At the conclusion of the experiment, participants were asked to complete an online sentence completion task designed to measure their knowledge of the soft mutation rule. In this task, participants were presented with a random subset of the experimental sentences, translated into Welsh. The Welsh target words were presented at the top of the screen, and the experimental sentences were presented underneath, with a blank space in place of the target word. Participants were instructed to type the target word in its grammatically correct form in the context of the sentence (i.e., mutated or not mutated). Correct responses were given a score of 1 , and participant performance was calculated by averaging across all test sentences. Participants included in the final analysis obtained an average score of $84 \%(S D=11 \%$; Range $=65-100 \%)$ on the mutation task. We note that this test measured participants' production of the mutation, and that task performance is comparable to previous studies measuring participants' production of accurate mutations (e.g. Thomas \& Gathercole, 2007; Vaughan-Evans et al., 2014).

\section{Results}




\section{Data analysis}

Data were analysed using linear mixed effects models using the lme4 package, version 1.1-12, (Bates, Maechler, Bolker \& Walker, 2015) in R version 3.2.3 (R Core Team, 2015). As our main predictions focused on the influence of sentence context on target word preview, we included an interaction term for these two factors when constructing each of our models. Our second prediction examined whether or not these factors were further modulated by phonological overlap on the target word. Thus, we used ANOVA comparisons to assess which model provided the best fit: Model 1, the full three-way interaction model (overlap* ${ }^{*}$ context* preview), Model 2 (additive contribution of phonological overlap: overlap + context* preview) or Model 3 (no contribution of phonological overlap: context*preview). For all eye-tracking measures, these comparisons showed that inclusion of phonological overlap did not contribute additional explanatory power, and we therefore report the findings of Model 3 for each analysis (context*preview).

In each analysis, mutation context sentences and identity previews comprised the baseline (intercept). 'Participants' and 'items' were included as random effects variables. The 'item', 'counterbalancing list', and 'item frequency' variables were modelled as a function of intercept performance, whilst the 'participant' variable included the intercept, plus the maximal slope of context*preview (Barr, Levy, Scheepers \& Tily, 2013). For all measures, the formal specification of our model was therefore:

$$
\begin{aligned}
& \text { DV } \sim \text { context*preview },+(1+\text { context } * \text { preview } \mid \text { Participant })+(1 \mid \text { Item }), \\
& +(1 \mid \text { counterbalancing list })+(1 \mid \text { item frequency }), \text { data }=[\text { dataframe }] .
\end{aligned}
$$


Treatment contrasts were used to interpret the model output, and the specifications of each model allowed for three fixed effects as well as the two interaction terms. Fixed Effect 1 compared identity preview trials in mutation and no mutation context sentences. Fixed Effect 2 compared identity preview trials with mutated preview trials in mutation context sentences. Fixed Effect 3 compared identity preview trials with aberrant preview trials in mutation context sentences. Of crucial interest were the two interaction terms. Interaction 1 assessed the extent to which differences in identity vs. mutated previews were specifically attributable to mutation context sentences vs. no mutation context sentences. Interaction 2 assessed the extent to which differences in identity vs. aberrant previews were specifically attributable to mutation context sentences vs. no mutation context sentences.

\section{Pre-processing of data}

Prior to data analysis, we excluded trials in which the boundary change was triggered early (prior to the saccade to the target), or in which participants did not fixate on the target word after the boundary change occurred. We additionally excluded trials in which the boundary change did not occur within $10 \mathrm{~ms}$ after fixation onset (e.g. Slattery, Angele \& Rayner, 2011), and fixations that were shorter than $80 \mathrm{~ms}$, or longer than $800 \mathrm{~ms}$. Given that the pre-target word region was often skipped (>40\% of trials), consistent with previous indications of skipping relating to short function words (Brysbaert, Drieghe \& Vitu, 2005; Hautala, Hyönä \& Aro, 2011; Rayner \& McConkie, 1976; Rayner, Slattery, Drieghe \& Liversedge, 2011; White, 2008), we extended the pre-target region to include both the pre-target word $(n-1)$ and the word preceding the pre-target word (n-2), resulting in a pre-target area with an average length of 8.19 characters. Crucially, the length of the pre-target region did not differ significantly 
between conditions (mutation context $=8.1$ characters; no mutation context $=8.31$ characters; $p=.64)$. Furthermore, as mutation context and no mutation context sentences were identical (with the exception of the pre-target word) the frequency and word length of the word preceding the pre-target were identical across conditions. Trials in which the pre-target region was skipped were not included in the analyses. In total, these exclusions resulted in the loss of $20.83 \%$ of all trials for our bilingual sample and $25.75 \%$ of all trials for our monolingual sample; a percentage loss that is consistent with previous studies implementing the boundary paradigm (e.g., Cutter, Drieghe \& Liversedge, 2014).

As is standard in eye tracking research, analyses were conducted on three interest areas: the pre-target region $(n-1 \& n-2)$, the target region $(n)$, and the post target region $(n+1)$, though note that our hypotheses are specific to the target region. For the pre-target and post-target regions, first fixation duration (the time spent initially fixating on a region) and gaze duration (the time spent fixating on a word before making a saccade to another region) were computed. Whilst analysing these regions is standard practice in the field, we make no specific predictions about the pattern of eye movements here, and as such, we consider these analyses as exploratory (cf. Nicenboim, Vasishth, Engelmann \& Suckow, 2018). For the target region, an additional two measures were computed: regression path duration (the sum of all fixations from the first fixation in a region until the first fixation to the right of that region), and rereading time (the time spent fixating the target word before making a saccade to the right of that region; Liversedge, Paterson \& Pickering, 1998). Given our strong predictions relating to the target region, we consider these analyses as confirmatory. For our bilingual sample, the means and standard deviations are shown in Table 4, and the beta values from the models for the pre-target, target, and post-target regions are 
displayed in Tables 6, 8, and 10, respectively. For our monolingual sample, the means and standard deviations are shown in Table 5, and the beta values from the models for the pre-target, target, and post-target regions are displayed in Tables 7, 9, and 11, respectively. For all our analyses, t-values greater than 1.96 are considered significant (e.g. Vorstius, Radach, Mayer \& Lonigan, 2013). With the exception of re-reading time, fixation durations were log-transformed prior to analysis to increase normality (Baayen, Davidson \& Bates, 2008), though we note that the pattern of results elicited by the raw data is comparable to the pattern of results elicited by the log transformed data.

[Table 4 near here]

[Table 5 near here]

Pre-target region

Welsh-English Bilinguals

A significant preview effect was observed: fixation times on the pre-target were longer for identity trials, compared with mutated and aberrant trials (see Table 6). A marginal interaction also emerged: Simple effects contrasts revealed that for mutation context sentences, marginally shorter gaze durations were observed on aberrant compared with identity preview trials (Estimate $=-0.03, S E=0.02, t=-1.44$ ). However, for no mutation context sentences, no significant difference was observed (Estimate $=0.01, S E$ $=0.02, t=0.36)$.

[Table 6 near here]

\section{English Monolinguals}

No significant effects were observed (see Table 7).

[Table 7 near here]

\section{Target region}

Welsh-English Bilinguals 
A significant preview benefit was observed, in which fixation times on the target were longer during mutated and aberrant preview trials, compared with identity preview trials (see Table 8). This effect occurred on all measures, with the exception of re-reading time, in which fixation times were longer during mutated preview trials but not aberrant preview trials, compared with identity preview trials. These preview effects demonstrate that our contingent change manipulation was effective.

A significant effect of sentence context was also observed: for identity preview trials, longer regression path durations were obtained during no mutation context sentences, compared with mutation context sentences. Importantly, an interaction was observed on regression path duration and re-reading time: Simple effects contrasts revealed that for mutation context sentences, longer regression path and re-reading times were observed on mutated compared with identity preview trials (Regression path: Estimate $=0.17, S E=0.03, t=5.84$; Re-reading: Estimate $=117.54, S E=60.46, t$ $=1.94)$. However, for no mutation context sentences, this difference was reduced for regression path duration (Estimate $=0.08, S E=0.02, t=3.47$ ), and no difference emerged for re-reading times (Estimate $=11.41, S E=48.35, t=0.24)$. The absence of a second interaction suggests that the difference between identity preview and aberrant preview trials was not significantly modulated by sentence context.

[Table 8 near here]

\section{English Monolinguals}

A significant preview benefit was observed, in which first fixation durations, gaze durations, and regression path durations on the target were longer during mutated and aberrant preview trials, compared with identity preview trials (see Table 9). These preview effects demonstrate that inconsistent linguistic input between parafoveal and 
foveal processing disrupted processing, and our contingent change manipulation was, therefore, effective.

A significant effect of sentence context was also observed: for identity preview trials, longer regression path durations were obtained for no mutation context sentences, compared with mutation context sentences. No significant interactions were observed.

[Table 9 near here]

\section{Post-target region}

Welsh-English Bilinguals

No significant effects were observed in this region (see Table 10).

[Table 10 near here]

\section{English Monolinguals}

A marginal effect of sentence context was observed for identity preview trials, such that longer gaze durations were obtained for mutation context sentences, compared with no mutation context sentences at the post-target region (see Table 11). No other significant effects were found.

[Table 11 near here]

\section{Additional analyses}

Our main analyses examined how preview of a nonword conforming to Welsh mutation rules altered reading behaviour compared with preview of an unaltered English word (identity preview). Preview of aberrant nonwords, which did not conform to Welsh mutation rules allowed us to ascertain whether mutations conferred a specific effect indicative of co-active syntax, or whether both categories of nonwords elicited comparable effects, suggestive of anomaly detection in both cases. Nevertheless, identity preview trials were modulated by sentence context in both monolinguals and 
bilinguals, and this supplementary analysis allowed us to examine evidence for coactivation without recourse to the identity preview trials. As such, we removed the identity previews from the models so as to enable a direct comparison between the mutated and aberrant previews in the target region. The results from these additional analyses are presented below.

\section{Welsh-English Bilinguals}

A significant preview effect was found, in which mutated previews yielded longer rereading times than aberrant previews (see Table 12). A marginally significant interaction was also found: Simple effects contrasts revealed that for mutation context sentences, longer re-reading times were observed on mutated compared with aberrant preview trials $($ Estimate $=-146.61, S E=56.94, t=2.56)$. However, for no mutation context sentences, no significant difference emerged (Estimate $=-3.95, S E=42.56, t=-$ 0.09). No other significant effects were observed.

[Insert Table 12 about here]

\section{English Monolinguals}

No significant effects were found (Table 13).

[Insert Table 13 about here]

\section{Discussion}

In this experiment, we examined whether bilinguals' syntax spontaneously co-activates during natural 'monolingual' English sentence reading, and whether such co-activation relies on lexical overlap between the two languages. We presented Welsh-English bilinguals with English sentences that would, or would not, elicit a mutation in Welsh 
(mutation sentence context vs. no mutation sentence context). Parafoveal preview of the target words - implemented using the boundary paradigm - was manipulated such that participants were presented with an identity preview (the target word in its original form; television), a mutated preview (the target word with an initial consonant switch consistent with the rules of soft mutation; delevision) or an aberrant preview (the target word with an initial consonant switch inconsistent with any of the rules of soft mutation; belevision).

Our analyses revealed that bilingual and monolingual participants were sensitive to the information provided in parafoveal preview (cf. Schotter, Angele \& Rayner, 2012): For 'identity preview' trials, which presented the same word in preview and upon explicit fixation, reading times in the target region were shorter compared to trials in which a change occurred, and therefore reflect a conventional preview effect, consistent with previous work implementing a contingent change manipulation (Rayner, 1975). In the pre-target region (for which we made no specific hypotheses), bilinguals and monolinguals showed a markedly different pattern of results. For bilinguals, shorter fixation durations were observed for mutated and aberrant preview trials compared with identity preview trials, providing evidence in support of parafoveal-on-foveal effects (cf. Pynte, Kennedy \& Ducrot, 2004). Pre-target region analyses also yielded a marginal interaction effect: When participants read an English sentence that would elicit a mutation in Welsh, preview of an aberrant word (e.g., belevision, which does not conform to mutation rules) yielded marginally shorter gaze durations than identity previews (e.g., television), however this difference was not present in sentences that would not elicit a mutation in Welsh. We suggest that in mutation context sentences, both identity and mutation previews were 'acceptable', as reflected in the eye movement behaviour, whereas readers were parafoveally sensitive to aberrant previews, 
and upon detection of an aberration, triggered an early saccade, presumably in an attempt to verify or disambiguate this information through early direct fixation of the target. In contrast, we found no parafoveal-on-foveal effects in our monolingual sample, with similar first fixation and gaze durations for identity, mutated, and aberrant trials in the pre-target region (cf. White \& Liversedge, 2004; Rayner, Juhasz \& Brown, 2007). The differing patterns observed here mirror the inconsistent findings of studies investigating PoF effects (Drieghe, 2011; Degno et al., 2019), and suggest that the linguistic profiles of participants may modulate PoF effects. One tentative explanation is that bilingual participants are more attentive to parafoveal information, given its salience for predicting upcoming changes in word-initial consonants. Thus, whilst these findings don't necessarily reflect syntactic co-activation, they do suggest that the linguistic rules of bilinguals' first language affect their reading patterns in the second language.

Analyses on target words revealed interactions in line with our main hypotheses: When bilingual participants were presented with a sentence that would elicit a soft mutation in Welsh, target words that were mutated according to soft mutation rules elicited longer re-reading times and regression path durations compared with identity preview trials. In addition, mutated previews elicited longer re-reading times than aberrant previews during mutation context sentences, yet no difference was observed during no mutation context sentences. These interaction effects (which were absent in our monolingual sample) notably occurred in measures associated with post-lexical stages of reading, suggesting that bilinguals first accessed the target word and then integrated it into the syntactic context of the sentence. Thus, whilst the data concur with our hypotheses, the results do not indicate predictive processing of words based on coactivation of syntax, in which effects on earlier reading measures might be expected. 
Rather, the longer reading times seen in later reading measures are likely indicative of momentary conflict between the rules of either language (Libben \& Titone, 2009). In this study, the mutated word encountered in parafoveal preview was consistent with Welsh morphosyntactic rules, but upon fixation, the target no longer adhered to this rule, leading to re-evaluation of the sentence according to English syntax. To draw an analogy with monolingual reanalysis procedures, the current findings are akin to initial misanalysis effects observed in garden path studies (e.g., Frazier, 1979). We propose that this conflict led to the observed disruption to processing and increased reading times, contra our previous findings (Vaughan-Evans et al., 2014).

The current data also shed light on the mechanism governing co-activation in natural reading. A consistent finding in the bilingual literature is that word recognition and reading times are facilitated as a function of lexical similarity across languages. For example, sentences that include cognates (translation equivalents that are orthographically similar across languages) typically yield faster reading times than sentences that include non-cognates (e.g. Van Assche, Duyck \& Hartsuiker, 2012; Van Assche, Duyck, Hartsuiker \& Diependaele, 2009; see Dijkstra, Grainger \& van Heuven, 1999 for similar effects during word recognition tasks). Such findings support language nonselective lexical access, as possible candidates from both languages are activated for selection on the basis of overlapping orthography (e.g. van Heuven, Dijkstra \& Grainger, 1998). However, the hypothesis that lexical cues trigger syntactic coactivation (e.g. Hatzidaki, Branigan \& Pickering, 2011) is countered by recent findings showing that syntactic co-activation occurs in the absence of lexical overlap (Kidd, Tennant \& Nitschke, 2015; Vaughan-Evans et al., 2014), suggesting that co-activation may be triggered by the syntactic rule. Here, phonological overlap did not modulate our 
effects, providing further evidence that the mechanism for syntactic co-activation can be non-lexical.

An interesting yet unexpected finding was that sentence context modulated regression path durations during identity preview trials, with shorter durations in mutation context sentences than in no mutation context sentences. This effect occurred despite the fact that identity preview trials comprised parafoveal preview of a normal English word, with no phonological manipulation. This effect occurred in both bilingual and monolingual groups, suggesting that slight differences in sentence construction between mutation and non-mutation conditions may have affected baseline differences in ease of grammatical processing (despite near-identical sentences and equivalent cloze probability values). However, monolinguals' shorter regression path reading times in mutation sentences were complemented by longer gaze durations on the post-target region, suggesting overall equivalent processing times between mutation and nonmutation sentences for this group. Such longer gaze durations were not found in the bilinguals, suggesting that for this group, mutation context sentences were easier to process overall. Further empirical work is needed to determine whether these effects reflect syntactic co-activation, or whether they reflect general baseline differences in ease of grammatical processing.

Whilst our overall findings provide support for syntactic co-activation during reading in bilinguals, it is questionable how robust the observed effects are. Bilinguals indeed showed differences in re-reading times for identity vs. mutated previews, and mutated vs. aberrant preview, modulated by sentence context, but the observed effects are small and the marginal differences observed between mutated and aberrant previews in our additional analyses should be interpreted cautiously. There may be a lack of statistical power, given the subtlety of the manipulation. Including more target words is 
not a feasible solution to obtain more power, given the highly constrained possibilities in stimulus selection. We suggest that future work might remove the identity preview condition to allow for more items in each experimental condition, and increased statistical power.

In conclusion, our findings provide tentative support for syntactic co-activation in the context of natural reading, and suggest that co-activation is triggered by a nonlexical mechanism during later stages of processing, in which the target word is integrated with the broader syntactic context. Further studies are now required to ascertain the robustness of this effect.

Acknowledgements: AVE and MWJ are associates of the Coleg Cymraeg Cenedlaethol (www.colegcymraeg.ac.uk). The authors declare no competing financial interests. 


\section{References}

Baayen, R. H., Davidson, D. J., \& Bates, D. M. (2008). Mixed-effects modeling with crossed random effects for subjects and items. Journal of Memory and Language, 59(4), 390-412. doi:10.1016/j.jml.2007.12.005

Ball, M. J., \& Müller, N. (1992). Mutation in Welsh. London, UK: Routledge.

Balota, D. A., Yap, M. J., Cortese, M. J., Hutchison, K. A., Kessler, B., Loftis, B., ... \& Treiman, R. (2007). The English lexicon project. Behavior research methods, 39(3), 445-459. doi:10.3758/BF03193014

Barr, D. J., Levy, R., Scheepers, C., \& Tily, H. J. (2013). Random effects structure for confirmatory hypothesis testing: Keep it maximal. Journal of Memory and Language, 68(3), 255-278. doi:10.1016/j.jml.2012.11.001

Bates, D., Maechler, M., Bolker, B., \& Walker, S. (2015). Fitting Linear Mixed-Effects Models Using lme4. Journal of Statistical Software, 67(1), 1-48. doi:10.18637/jss.v067.i01

Bernolet, S., \& Hartsuiker, R. J. (2018). Syntactic representations in late learners of a second language: The state of the science across its subfields. In D. Miller, F. Bayram, J. Rothman, \& L. Serratrice (Eds.), Bilingual Cognition and Language: The state of the science across its subfields (pp. 205-224). The Netherlands: John Benjamins. doi:10.1075/sibil.54.10ber

Bernolet, S., Hartsuiker, R. J., \& Pickering, M. J. (2007). Shared syntactic representations in bilinguals: Evidence for the role of word-order repetition. Journal of Experimental Psychology: Learning, Memory, and Cognition, 33(5), 931-949. doi:10.1037/0278-7393.33.5.931

Bernolet, S., Hartsuiker, R. J., \& Pickering, M. J. (2013). From language-specific to shared syntactic representations: The influence of second language proficiency 
on syntactic sharing in bilinguals. Cognition, 127(3), 287-306.

doi:10.1016/j.cognition.2013.02.005

Brysbaert, M., Drieghe, D., \& Vitu, F. (2005). Word skipping: implications for theories of eye movement control in reading. In G. Underwood (Ed.), Cognitive Processes in Eye Guidance (pp. 53-77). Oxford, UK: Oxford University Press.

Cutter, M.G., Drieghe, D., \& Liversedge, S.P. (2014). Preview benefit in English spaced compounds. Journal of Experimental Psychology: Learning, Memory, and Cognition, 40(6), 1778-1786. doi:10.1037/xlm0000013

Degno, F., Loberg, O., Zang, C., Zhang, M., Donnelly, N., \& Liversedge, S. P. (2019). Parafoveal previews and lexical frequency in natural reading: Evidence from eye movements and fixation-related potentials. Journal of Experimental Psychology: General, 148(3), 453-474. doi:10.1037/xge0000494

Dijkstra, T., Grainger, J., \& Van Heuven, W. J. B. (1999). Recognition of cognates and interlingual homographs: The neglected role of phonology. Journal of Memory and language, 41(4), 496-518. doi:10.1006/jmla.1999.2654

Dijkstra, T., \& van Heuven, W. J. B. (1998). The BIA model and bilingual word recognition. In J. Grainger \& A. M. Jacobs (Eds.), Localist connectionist approaches to human cognition (pp. 189-225). Hillsdale, NJ: Lawrence Erlbaum Associates.

Drieghe, D. (2011). Parafoveal-on-foveal effects on eye movements during reading. In S. P. Liversedge, I. D. Gilchrist, \& S. Everling (Eds.), Oxford library of psychology. The Oxford handbook of eye movements (p. 839-855). Oxford University Press.

Duyck, W. (2005). Translation and associative priming with cross-lingual pseudohomophones: evidence for nonselective phonological activation in 
bilinguals. Journal of Experimental Psychology: Learning, Memory, and Cognition, 31(6), 1340-1359. doi:10.1037/D278-7393.31.6.1340

Frazier, L. (1979). On comprehending sentences: Syntactic parsing strategies (Unpublished doctoral dissertation). University of Connecticut, Connecticut.

Frenck-Mestre, C., \& Pynte, J. (1997). Syntactic ambiguity resolution while reading in second and native languages. Quarterly Journal of Experimental Psychology, 50, 119-148. doi:10.1080/027249897392251

Gerard, L. D., \& Scarborough, D. L. (1989). Language-specific lexical access of homographs by bilinguals. Journal of Experimental Psychology: Learning, Memory, and Cognition, 15(2), 305-315. doi:10.1037/D278-7393.15.2.305

Grosjean, F. (1998). Studying bilinguals: Methodological and conceptual issues. Bilingualism: Language and cognition, 1(02), 131-149. doi:10.1017/S136672899800025X

Harlow, S. (1989). The syntax of Welsh soft mutation. Natural Language and Linguistic Theory, 7(3), 289-316. Retrieved from http://www.jstor.org/stable/4047721

Hartsuiker, R. J., \& Bernolet, S. (2016). The development of shared syntax in second language learning. Bilingualism: Language and Cognition. Advance online publication. doi:10.1017/S1366728915000164

Hartsuiker, R. J., \& Pickering, M. J. (2008). Language integration in bilingual sentence production. Acta Psychologica, 128(3), 479-489. doi:10.1016/j.actpsy.2007.08.005

Hartsuiker, R. J., Pickering, M. J., \& Veltkamp, E. (2004). Is syntax separate or shared between languages? Cross-linguistic syntactic priming in Spanish-English 
bilinguals. Psychological Science, 15(6), 409-414. doi:10.1111/j.09567976.2004.00693.x

Hatzidaki, A., Branigan, H. P., \& Pickering, M. J. (2011). Co-activation of syntax in bilingual language production. Cognitive Psychology, 62(2), 123-150. doi:10.1016/j.cogpsych.2010.10.002

Hautala, J., Hyönä, J., \& Aro, M. (2011). Dissociating spatial and letter-based word length effects observed in readers' eye movement patterns. Vision Research, 51(15), 1719-1727. doi:10.1016/j.visres.2011.05.015

Hopp, H. (2017). Cross-linguistic lexical and syntactic co-activation in L2 sentence processing. Linguistic Approaches to Bilingualism, 7(1), 96-130. doi:10.1075/lab.14027.hop

Jared, D., \& Kroll, J. F. (2001). Do bilinguals activate phonological representations in one or both of their languages when naming words? Journal of Memory and Language, 44(1), 2-31. doi:10.1006/jmla.2000.2747

Kaushanskaya, M., \& Smith, S. (2016). Do grammatical-gender distinctions learned in the second language influence native-language lexical processing? International Journal of Bilingualism, 20, 30-39. doi:10.1177/1367006915576830

Kidd, E., Tennant, E., \& Nitschke, S. (2015). Shared abstract representation of linguistic structure in bilingual sentence comprehension. Psychonomic Bulletin and Review, 22(4), 1062-1067. doi:10.3758/s13423-014-0775-2

Lauro, J., \& Schwartz, A.I. (2017). Bilingual non-selective lexical access in sentence contexts: A meta-analytic review. Journal of Memory and Language, 92, 217233. doi: 10.1016/j.jml.2016.06.010

Lemhöfer, K., \& Dijkstra, T. (2004). Recognizing cognates and interlingual homographs: Effects of code similarity in language-specific and generalized 
lexical decision. Memory and Cognition, 32(4), 533-550.

doi:10.3758/BF03195845

Libben, M. R., \& Titone, D. A. (2009). Bilingual lexical access in context: Evidence from eye movements during reading. Journal of Experimental Psychology: Language, Memory, and Cognition, 35(2), 381-390. doi:10.1037/a0014875

Liversedge, S. P., Paterson, K. B., \& Pickering, M. J. (1998). Eye movements and measures of reading time. In G. Underwood (Ed.), Eye guidance in reading and scene perception (pp. 55-75). Oxford, UK: Elsevier Science.

Lund, K., \& Burgess, C. (1996). Producing high-dimensional semantic spaces from lexical co-occurrence. Behavior Researrch Methods, Instruments, and Computers, 28(2), 203-208. doi:10.3758/BF03204766

Mercier, J., Pivneva, I., \& Titone, D. (2015). The role of prior language context on bilingual spoken word processing: Evidence from the visual world task. Bilingualism: Language and Cognition, 19(2), 376-399. doi:10.1017/S1366728914000340

Morales, L., Paolieri, D., Cubelli, R., \& Bajo, T. (2014). Transfer of Spanish grammatical gender to English: Evidence from immersed and non-immersed bilinguals. Bilingualism: Language and Cognition, 17(4), 700-708. doi:10.1017/S1366728914000017

Nicenboim, B., Vasishth, S., Engelmann, F., \&Suckow, K. (2018). Exploratory and confirmatory analyses in sentence processing: A case study of number interference in German. Cognitive Science, 42(54), 1075-1100. doi:10.1111/cogs. 12589 
Pynte, J., Kennedy, A., \& Ducrot, S. (2004). The influence of parafoveal typographical errors on eye movements in reading. European Journal of Cognitive Psychology, 16, 178-202, doi: 10.1080/09541440340000169

R Core Team. (2015). R: A language and environment for statistical computing. Vienna, Austria: R Foundation for Statistical Computing. Retrieved from http://www.R-project.org/

Rayner, K. (1975). The perceptual span and peripheral cues in reading. Cognitive Psychology, 7(1), 65-81. doi:10.1016/0010-0285)75)90005-5

Rayner, K. (2009). Eye movements and attention in reading, scene perception, and visual search. The Quarterly Journal of Experimental Psychology, 62(8), $1457-$ 1506. doi:10.1080/17470210902816461

Rayner, K., Juhasz, B. J., \& Brown, S. J. (2007). Do readers obtain preview benefit from word $\mathrm{N}+2$ ? A test of serial attention shift versus distributed lexical processing models of eye movement control in reading. Journal of Experimental Psychology: Human Perception and Performance, 33, 230245. doi:10.1037/0096-1523.33.1.230

Rayner, K., \& McConkie, G. W. (1976). What guides a reader's eye movements? Vision Research, 16(8), 829-837. doi:10.1016/0042-6989(76)90143-7

Rayner, K., Slattery, T. J., Drieghe, D., \& Liversedge, S. P. (2011). Eye movements and word skipping during reading: Effects of word length and predictability. Journal of Experimental Psychology: Human Perception and Performance, 37(2), 514528. doi: $10.1037 / \mathrm{a} 0020990$

Sanoudaki, E., \& Thierry, G. (2014). Juggling two grammars. In E. M. Thomas \& I. Mennen (Eds.), Advances in the study of bilingualism (pp. 214-230). Bristol, UK: Multilingual Matters. 
Sanoudaki, E., \& Thierry, G. (2015). Language non-selective syntactic activation in early bilinguals: the role of verbal fluency. International Journal of Bilingual Education and Bilingualism, 18(5), 548-560.

doi:10.1080/13670050.2015.1027143

Schotter, E. R., Angele, B., \& Rayner, K. (2012). Parafoveal processing in reading. Attention, Perception, and Psychophysics, 74(1), 5-35. doi:10.3758/s13414-011$0219-2$

Slattery, T. J., Angele, B., \& Rayner, K. (2011). Eye movements and display change detection during reading. Journal of Experimental Psychology: Human Perception and Performance, 37(6), 1924-1938. doi:10.1037/a0024322

Soares, C., \& Grosjean, F. (1984). Bilinguals in a monolingual and a bilingual speech mode: The effect on lexical access. Memory and Cognition, 12(4), 380-386. doi:10.3758/BF03198298

Thierry, G., \& Wu, Y. J. (2007). Brain potentials reveal unconscious translation during foreign-language comprehension. Proceedings of the National Academy of Sciences, 104(30), 12530-12535. doi:10.1073/pnas.0609927104

Thomas, E.M., \& Gathercole, V.C.M. (2007). Children's productive command of grammatical gender and mutation in Welsh: An alternative to rule-based learning. First Language, 27(3), 251-278. doi:10.1177/01427237077056

Van Assche, E., Duyck, W., \& Hartsuiker, R. J. (2012). Bilingual word recognition in a sentence context. Frontiers in Psychology, 3. doi:10.3389/fpsyg.2012.00174

Van Assche, E., Duyck, W., Hartsuiker, R. J., \& Diependaele, K. (2009). Does bilingualism change native-language reading? Psychological Science, 20(8), 923-927. doi:10.1111/j.1467-9280.2009.02389.x 
Van Heuven, W. J. B., Dijkstra, T., \& Grainger, J. (1998). Orthographic neighborhood effects in bilingual word recognition. Journal of Memory and Language, 29(3), 458-483. doi:10.1006/jmla.1998.2584

Vaughan-Evans, A., Thierry, G., Kuipers, J. -R., \& Jones, M.W. (2014). Anomalous transfer of syntax between languages. The Journal of Neuroscience, 34(24), 8333-8335. doi:10.1523/JNEUROSCI.0665-14.2014

Vorstius, C., Radach, R., Mayer, M. B., \& Lonigan, C. J. (2013). Monitoring local comprehension monitoring in sentence reading. School Psychology Review, 42(2), 191-206.

White, S. (2008). Eye movement control during reading: Effects of word frequency and orthographic familiarity. Journal of Experimental Psychology: Human Perception and Performance, 34, 205 - 223. doi: 10.1037/0096-1523.34.1.205

White, S. J., \& Liversedge, S. P. (2004). Orthographic familiarity influences initial eye fixation positions in reading. The European Journal of Cognitive Psychology, 16, 52-78. doi: 10.1080/09541440340000204

Whitford, V., \& Titone, D. (2016). Eye movements and the perceptual span during firstand second-language sentence reading in bilingual older adults. Psychology and Aging, 31(1), 58-70. doi:10.1037/a0039971 
Table 1. Experimental design and stimulus examples.

\section{Overlap Target Word}

Mutation context sentences

Identity preview Steve was allowed to watch his:television after completing his homework

Mutated preview Steve was allowed to watch his:delevision after completing his homework

Aberrant preview Steve was allowed to watch his

Welsh translation Cafodd Steve wylio ei deledu wedi iddo orffen ei waith cartref

\section{No Mutation context sentences}

Identity preview Steve was allowed to watch thelevision after completing his homework

Mutated preview Steve was allowed to watch the delevision after completing his homework

Aberrant preview Steve was allowed to watch the belevision after completing his homework

Welsh translation Cafodd Steve wylio'r teledu wedi iddo orffen ei waith cartref

\section{No Overlap Target Word}

Mutation context sentences

Identity preview On Shrove Tuesday, the family ate many: pancakes instead of eating supper

Mutated preview On Shrove Tuesday, the family ate many: bancakes instead of eating supper

Aberrant preview On Shrove Tuesday, the family ate many dancakes instead of eating supper

Welsh translation Ar ddydd Mawrth Ynyd, bwytaodd y teulu nifer o grempogau yn lle swper

\section{No mutation context sentences}

Identity preview On Shrove Tuesday, the family ate four:pancakes instead of eating supper

Mutated preview On Shrove Tuesday, the family ate four:bancakes instead of eating supper

Aberrant preview On Shrove Tuesday, the family ate four:dancakes instead of eating supper

Welsh translation Ar ddydd Mawrth Ynyd, bwytaodd y teulu bedwar crempog yn lle swper

Note. Welsh translations are included for illustrative purposes only. 
Table 2. Word length and frequency ratings for the pre-target words.

\begin{tabular}{lllll}
\hline & \multicolumn{2}{c}{ Overlap } & \multicolumn{2}{c}{ No Overlap } \\
\hline & $\begin{array}{l}\text { Mutation } \\
\text { Context }\end{array}$ & $\begin{array}{l}\text { No Mutation } \\
\text { Context }\end{array}$ & $\begin{array}{l}\text { Mutation } \\
\text { Context }\end{array}$ & $\begin{array}{l}\text { No Mutation } \\
\text { Context }\end{array}$ \\
\hline Word Length & $M=3.29$ & $M=3.42$ & $M=3.31$ & $M=3.48$ \\
(characters) & $S D=0.46$ & $S D=0.65$ & $S D=0.47$ & $S D=0.65$ \\
\hline Word & $M=13.48$ & $M=14.35$ & $M=13.57$ & $M=13.66$ \\
Frequency & $S D=0.96$ & $S D=2.84$ & $S D=1.07$ & $S D=2.81$ \\
\hline
\end{tabular}


Table 3. Word length and frequency ratings for the target words.

\begin{tabular}{lll}
\hline & Overlap & No Overlap \\
\hline Word Length & $M=7.96$ & $M=7.58$ \\
(characters) & $S D=2.04$ & $S D=2.09$ \\
\hline Word & $M=9.23$ & $M=8.67$ \\
Frequency & $S D=1.54$ & $S D=1.46$ \\
\hline
\end{tabular}


Table 4. Reading times (ms) of Welsh-English bilinguals across all experimental conditions for all target regions.

\begin{tabular}{|c|c|c|c|c|c|c|c|c|c|c|c|c|}
\hline & \multicolumn{6}{|c|}{ Mutation context sentences } & \multicolumn{6}{|c|}{ No mutation context sentences } \\
\hline & \multicolumn{2}{|c|}{$\begin{array}{l}\text { Identity } \\
\text { preview }\end{array}$} & \multicolumn{2}{|c|}{$\begin{array}{l}\text { Mutated } \\
\text { preview }\end{array}$} & \multicolumn{2}{|c|}{$\begin{array}{l}\text { Aberrant } \\
\text { preview }\end{array}$} & \multicolumn{2}{|c|}{$\begin{array}{l}\text { Identity } \\
\text { preview }\end{array}$} & \multicolumn{2}{|c|}{$\begin{array}{l}\text { Mutated } \\
\text { preview }\end{array}$} & \multicolumn{2}{|c|}{$\begin{array}{c}\text { Aberrant } \\
\text { preview }\end{array}$} \\
\hline & $M$ & $S D$ & $M$ & $S D$ & $M$ & $S D$ & $M$ & $S D$ & $M$ & $S D$ & $M$ & $S D$ \\
\hline & \multicolumn{12}{|c|}{ First fixation duration } \\
\hline Pre-target region & 234 & 78 & 224 & 69 & 226 & 72 & 232 & 76 & 225 & 72 & 226 & 64 \\
\hline Target region & 222 & 68 & 234 & 72 & 232 & 68 & 224 & 73 & 242 & 77 & 241 & 76 \\
\hline \multirow[t]{2}{*}{ Post target region } & 225 & 64 & 226 & 70 & 228 & 73 & 230 & 76 & 231 & 79 & 231 & 71 \\
\hline & \multicolumn{12}{|c|}{ Gaze duration } \\
\hline Pre-target region & 349 & 206 & 330 & 180 & 333 & 182 & 339 & 174 & 340 & 186 & 354 & 193 \\
\hline Target region & 298 & 158 & 328 & 162 & 336 & 173 & 312 & 162 & 331 & 151 & 336 & 145 \\
\hline \multirow{2}{*}{ Post target region } & 251 & 92 & 258 & 105 & 252 & 94 & 259 & 107 & 258 & 103 & 267 & 119 \\
\hline & \multicolumn{12}{|c|}{ Regression path duration } \\
\hline Pre-target region & - & - & - & - & - & - & - & - & - & - & - & - \\
\hline Target region & 325 & 186 & 386 & 256 & 380 & 209 & 357 & 221 & 370 & 193 & 381 & 202 \\
\hline \multirow[t]{2}{*}{ Post target region } & - & - & - & - & - & - & - & - & - & - & - & - \\
\hline & \multicolumn{12}{|c|}{ Re-reading time } \\
\hline Pre-target region & - & - & - & - & - & - & - & - & - & - & - & - \\
\hline Target region & 326 & 231 & 436 & 437 & 333 & 238 & 424 & 327 & 403 & 277 & 392 & 260 \\
\hline Post target region & - & - & - & - & - & - & - & - & - & - & - & - \\
\hline
\end{tabular}

Note. Regression path duration, and re-reading time measures were not computed for the pre- and post-target regions. 
Table 5. Reading times (ms) of English monolinguals across all experimental conditions for all target regions.

\begin{tabular}{|c|c|c|c|c|c|c|c|c|c|c|c|c|}
\hline & \multicolumn{6}{|c|}{ Mutation context sentences } & \multicolumn{6}{|c|}{ No mutation context sentences } \\
\hline & \multicolumn{2}{|c|}{$\begin{array}{l}\text { Identity } \\
\text { preview }\end{array}$} & \multicolumn{2}{|c|}{$\begin{array}{l}\text { Mutated } \\
\text { preview }\end{array}$} & \multicolumn{2}{|c|}{$\begin{array}{l}\text { Aberrant } \\
\text { preview }\end{array}$} & \multicolumn{2}{|c|}{$\begin{array}{l}\text { Identity } \\
\text { preview }\end{array}$} & \multicolumn{2}{|c|}{$\begin{array}{l}\text { Mutated } \\
\text { preview }\end{array}$} & \multicolumn{2}{|c|}{$\begin{array}{l}\text { Aberrant } \\
\text { preview }\end{array}$} \\
\hline & $M$ & $S D$ & $M$ & $S D$ & $M$ & $S D$ & $M$ & $S D$ & $M$ & $S D$ & $M$ & $S D$ \\
\hline & \multicolumn{12}{|c|}{ First fixation duration } \\
\hline Pre-target region & 220 & 75 & 221 & 73 & 222 & 67 & 225 & 82 & 225 & 80 & 221 & 80 \\
\hline Target region & 222 & 72 & 232 & 74 & 237 & 80 & 228 & 77 & 233 & 75 & 238 & 72 \\
\hline \multirow[t]{2}{*}{ Post target region } & 227 & 73 & 225 & 69 & 229 & 78 & 224 & 69 & 224 & 79 & 223 & 79 \\
\hline & \multicolumn{12}{|c|}{ Gaze duration } \\
\hline Pre-target region & 304 & 173 & 313 & 182 & 305 & 162 & 302 & 158 & 313 & 158 & 303 & 162 \\
\hline Target region & 269 & 123 & 290 & 115 & 298 & 131 & 287 & 143 & 301 & 133 & 301 & 126 \\
\hline \multirow[t]{2}{*}{ Post target region } & 264 & 114 & 254 & 94 & 256 & 100 & 252 & 99 & 251 & 105 & 253 & 105 \\
\hline & \multicolumn{12}{|c|}{ Regression path duration } \\
\hline Pre-target region & - & - & - & - & - & - & - & - & - & - & - & - \\
\hline Target region & 328 & 219 & 370 & 228 & 373 & 220 & 361 & 251 & 376 & 209 & 381 & 239 \\
\hline \multirow[t]{2}{*}{ Post target region } & - & - & - & - & - & - & - & - & - & - & - & - \\
\hline & \multicolumn{12}{|c|}{ Re-reading time } \\
\hline Pre-target region & - & - & - & - & - & - & - & - & - & - & - & - \\
\hline Target region & 352 & 318 & 374 & 310 & 396 & 276 & 433 & 371 & 376 & 236 & 414 & 355 \\
\hline Post target region & - & - & - & - & - & - & - & - & - & - & - & - \\
\hline
\end{tabular}

Note. Regression path duration, and re-reading time measures were not computed for the pre- and post-target regions. 
Table 6. Fixed effect estimates derived from the linear mixed effects models for all measures in the pre-target region for Welsh-English bilinguals.

\begin{tabular}{lcccccc}
\hline & \multicolumn{3}{c}{ First fixation duration } & \multicolumn{3}{c}{ Gaze duration } \\
\hline & Estimate & Std. Error & $\mathrm{t}$ value & Estimate & Std. Error & $\mathrm{t}$ value \\
Intercept & 5.405 & 0.021 & 252.687 & 5.704 & 0.044 & 130.743 \\
Context & -0.010 & 0.017 & -0.623 & -0.012 & 0.024 & -0.495 \\
$\begin{array}{l}\text { Preview (Mutated) } \\
\text { Preview (Aberrant) }\end{array}$ & -0.035 & 0.016 & -2.214 & -0.037 & 0.024 & -1.502 \\
$\begin{array}{l}\text { Context*Preview } \\
\text { (Mutated) }\end{array}$ & 0.032 & 0.016 & -2.048 & -0.039 & 0.023 & -1.682 \\
$\begin{array}{l}\text { Context*Preview } \\
\text { (Aberrant) }\end{array}$ & 0.016 & 0.022 & 0.393 & 0.038 & 0.033 & 1.133 \\
\hline$t>1.65 ; p<.1$. & $t>1.96 ; p<.05$. & $t>2.56 ; p<.01$. & $t>3.29 ; p<.001$. & \\
\end{tabular}


Table 7. Fixed effect estimates derived from the linear mixed effects models for all measures in the pre-target region for English monolinguals.

\begin{tabular}{lcccccc}
\hline & \multicolumn{3}{c}{ First fixation duration } & \multicolumn{3}{c}{ Gaze duration } \\
\hline & Estimate & Std. Error & $\mathrm{t}$ value & Estimate & Std. Error & $\mathrm{t}$ value \\
Intercept & 5.340 & 0.022 & 240.742 & 5.572 & 0.037 & 150.173 \\
Context & 0.006 & 0.019 & 0.347 & -0.008 & 0.025 & -0.324 \\
$\begin{array}{l}\text { Preview (Mutated) } \\
\text { Preview (Aberrant) }\end{array}$ & 0.008 & 0.018 & 0.460 & 0.025 & 0.028 & 0.879 \\
$\begin{array}{l}\text { Context*Preview } \\
\text { (Mutated) }\end{array}$ & 0.002 & 0.018 & 0.571 & 0.010 & 0.027 & 0.376 \\
$\begin{array}{l}\text { Context*Preview } \\
\text { (Aberrant) }\end{array}$ & -0.018 & 0.026 & 0.060 & 0.018 & 0.037 & 0.492 \\
\hline$t>1.65 ; p<.1$. & $t>1.96 ; p<.05$. & $t>2.56 ; p<.01$. & $t>3.29 ; p<.001$. & 0.145 \\
\end{tabular}


Table 8. Fixed effect estimates derived from the linear mixed effects models for all measures in the target region for Welsh-English bilinguals.

\begin{tabular}{|c|c|c|c|c|c|c|}
\hline & \multicolumn{3}{|c|}{ First fixation duration } & \multicolumn{3}{|c|}{ Gaze duration } \\
\hline & Estimate & Std. Error & $\mathrm{t}$ value & Estimate & Std. Error & t value \\
\hline Intercept & 5.360 & 0.019 & 279.773 & 5.578 & 0.032 & 173.905 \\
\hline Context & 0.002 & 0.016 & 0.143 & 0.032 & 0.023 & 1.413 \\
\hline Preview (Mutated) & 0.054 & 0.018 & 3.074 & 0.104 & 0.025 & 4.142 \\
\hline Preview (Aberrant) & 0.050 & 0.016 & 3.189 & 0.124 & 0.022 & 5.658 \\
\hline $\begin{array}{l}\text { Context*Preview } \\
\text { (Mutated) }\end{array}$ & 0.020 & 0.022 & 0.925 & -0.010 & 0.038 & -0.251 \\
\hline $\begin{array}{l}\text { Context*Preview } \\
\text { (Aberrant) }\end{array}$ & 0.027 & 0.022 & 1.213 & -0.016 & 0.033 & -0.482 \\
\hline & \multicolumn{3}{|c|}{ Regression path duration } & \multicolumn{3}{|c|}{ Re-reading time } \\
\hline & Estimate & Std. Error & $\mathrm{t}$ value & Estimate & Std. Error & t value \\
\hline Intercept & 5.652 & 0.034 & 164.560 & 342.345 & 40.401 & 8.474 \\
\hline Context & 0.063 & 0.026 & 2.445 & 106.206 & 55.664 & 1.908 \\
\hline Preview (Mutated) & 0.159 & 0.028 & 5.599 & 156.021 & 78.774 & 1.981 \\
\hline Preview (Aberrant) & 0.163 & 0.025 & 6.609 & -6.486 & 44.476 & -0.146 \\
\hline $\begin{array}{l}\text { Context*Preview } \\
\text { (Mutated) } \\
\text { Context*Preview }\end{array}$ & -0.074 & 0.038 & -1.966 & -182.213 & 95.421 & -1.91 \\
\hline (Aberrant) & -0.060 & 0.036 & -1.665 & -54.635 & 67.034 & -0.815 \\
\hline
\end{tabular}


Table 9. Fixed effect estimates derived from the linear mixed effects models for all measures in the target region for English monolinguals.

\begin{tabular}{|c|c|c|c|c|c|c|}
\hline & \multicolumn{3}{|c|}{ First fixation duration } & \multicolumn{3}{|c|}{ Gaze duration } \\
\hline & Estimate & Std. Error & $\mathrm{t}$ value & Estimate & Std. Error & t value \\
\hline Intercept & 5.352 & 0.026 & 205.347 & 5.494 & 0.043 & 126.925 \\
\hline Context & 0.020 & 0.023 & 0.902 & 0.052 & 0.029 & 1.818 \\
\hline Preview (Mutated) & 0.049 & 0.019 & 2.507 & 0.105 & 0.023 & 4.495 \\
\hline Preview (Aberrant) & 0.060 & 0.019 & 3.132 & 0.110 & 0.025 & 4.460 \\
\hline $\begin{array}{l}\text { Context*Preview } \\
\text { (Mutated) }\end{array}$ & -0.013 & 0.029 & -0.466 & -0.027 & 0.035 & -0.775 \\
\hline $\begin{array}{l}\text { Context*Preview } \\
\text { (Aberrant) }\end{array}$ & -0.005 & 0.029 & -0.175 & -0.026 & 0.036 & -0.725 \\
\hline & \multicolumn{3}{|c|}{ Regression path duration } & \multicolumn{3}{|c|}{ Re-reading time } \\
\hline & Estimate & Std. Error & t value & Estimate & Std. Error & t value \\
\hline Intercept & 5.635 & 0.051 & 109.713 & 341.77 & 37.92 & 9.013 \\
\hline Context & 0.083 & 0.029 & 2.850 & 71.37 & 44.07 & 1.62 \\
\hline Preview (Mutated) & 0.150 & 0.027 & 5.472 & 45.06 & 44.98 & 1.002 \\
\hline Preview (Aberrant) & 0.149 & 0.027 & 5.542 & 46.29 & 41.06 & 1.127 \\
\hline $\begin{array}{l}\text { Context*Preview } \\
\text { (Mutated) } \\
\text { Context*Preview }\end{array}$ & -0.058 & 0.038 & -1.513 & -79.83 & 59.79 & -1.335 \\
\hline (Aberrant) & -0.056 & 0.039 & -1.441 & -31.42 & 61.15 & -0.514 \\
\hline
\end{tabular}


Table 10. Fixed effect estimates derived from the linear mixed effects models for all measures in the post-target region for Welsh-English bilinguals.

\begin{tabular}{|c|c|c|c|c|c|c|}
\hline & \multicolumn{3}{|c|}{ First fixation duration } & \multicolumn{3}{|c|}{ Gaze duration } \\
\hline & Estimate & Std. Error & $\mathrm{t}$ value & Estimate & Std. Error & t value \\
\hline Intercept & 5.375 & 0.022 & 245.129 & 5.456 & 0.026 & 210.402 \\
\hline Context & 0.019 & 0.017 & 1.148 & 0.024 & 0.020 & 1.226 \\
\hline Preview (Mutated) & 0.007 & 0.019 & 0.347 & 0.019 & 0.023 & 0.819 \\
\hline Preview (Aberrant) & 0.006 & 0.017 & 0.349 & 0.001 & 0.020 & 0.060 \\
\hline $\begin{array}{l}\text { Context*Preview } \\
\text { (Mutated) } \\
\text { Context*Preview }\end{array}$ & -0.009 & 0.028 & -0.319 & -0.011 & 0.033 & -0.347 \\
\hline (Aberrant) & 0.001 & 0.025 & 0.049 & 0.020 & 0.029 & 0.704 \\
\hline
\end{tabular}


Table 11. Fixed effect estimates derived from the linear mixed effects models for all measures in the post-target region for English monolinguals.

\begin{tabular}{lcccccc}
\hline & \multicolumn{3}{c}{ First fixation duration } & \multicolumn{3}{c}{ Gaze duration } \\
\hline & Estimate & Std. Error & $t$ value & Estimate & Std. Error & $t$ value \\
Intercept & 5.362 & 0.023 & 233.082 & 5.477 & 0.029 & 191.648 \\
Context & -0.020 & 0.023 & -0.879 & -0.047 & 0.024 & -1.932 \\
$\begin{array}{l}\text { Preview (Mutated) } \\
\text { Preview (Aberrant) }\end{array}$ & -0.004 & 0.022 & -0.160 & -0.021 & 0.024 & -0.858 \\
$\begin{array}{l}\text { Context*Preview } \\
\text { (Mutated) }\end{array}$ & 0.008 & 0.023 & 0.115 & -0.019 & 0.025 & -0.761 \\
$\begin{array}{l}\text { Context*Preview } \\
\text { (Aberrant) }\end{array}$ & -0.006 & 0.032 & 0.261 & 0.024 & 0.035 & 0.689 \\
\hline$t>1.65 ; p<.1$. & $t>1.96 ; p<.05$. & $t>2.56 ; p<.01$. & $t>3.29 ; p<.001$. & \\
\end{tabular}


Table 12. Fixed effect estimates derived from the linear mixed effects models for all measures in the target region for Welsh-English bilinguals. Mutation context sentences and mutated previews comprised the baseline (intercept).

\begin{tabular}{|c|c|c|c|c|c|c|}
\hline & \multicolumn{3}{|c|}{ First fixation duration } & \multicolumn{3}{|c|}{ Gaze duration } \\
\hline & Estimate & Std. Error & $\mathrm{t}$ value & Estimate & Std. Error & t value \\
\hline Intercept & 5.415 & 0.019 & 278.468 & 5.688 & 0.037 & 155.429 \\
\hline Context & 0.023 & 0.016 & 1.497 & 0.017 & 0.026 & 0.659 \\
\hline Preview (Aberrant) & -0.005 & 0.016 & -0.283 & 0.019 & 0.021 & 0.935 \\
\hline $\begin{array}{l}\text { Context*Preview } \\
\text { (Aberrant) }\end{array}$ & 0.007 & 0.023 & 0.317 & -0.006 & 0.030 & -0.198 \\
\hline & \multicolumn{3}{|c|}{ Regression path duration } & \multicolumn{3}{|c|}{ Re-reading time } \\
\hline & Estimate & Std. Error & t value & Estimate & Std. Error & t value \\
\hline Intercept & 5.815 & 0.040 & 146.520 & 509.67 & 83.72 & 6.088 \\
\hline Context & -0.013 & 0.024 & -0.532 & -107.78 & 86.82 & -1.241 \\
\hline Preview (Aberrant) & 0.004 & 0.023 & 0.177 & -179.49 & 81.5 & -2.202 \\
\hline $\begin{array}{l}\text { Context*Preview } \\
\text { (Aberrant) }\end{array}$ & 0.013 & 0.032 & 0.415 & 161.87 & 90.61 & 1.786 \\
\hline
\end{tabular}


Table 13. Fixed effect estimates derived from the linear mixed effects models for all measures in the target region for English monolinguals. Mutation context sentences and mutated previews comprised the baseline (intercept).

\begin{tabular}{lcccccc}
\hline & \multicolumn{3}{c}{ First fixation duration } & \multicolumn{3}{c}{ Gaze duration } \\
\hline & Estimate & Std. Error & $\mathrm{t}$ value & Estimate & Std. Error & $\mathrm{t}$ value \\
Intercept & 5.401 & 0.024 & 225.926 & 5.600 & 0.036 & 154.639 \\
Context & 0.007 & 0.019 & 0.352 & 0.025 & 0.024 & 1.062 \\
Preview (Aberrant) & 0.012 & 0.019 & 0.629 & 0.010 & 0.023 & 0.425 \\
$\begin{array}{l}\text { Context*Preview } \\
\text { (Aberrant) }\end{array}$ & 0.009 & 0.026 & 0.332 & -0.002 & 0.031 & -0.074 \\
\hline \multicolumn{7}{c}{ Regression path duration } \\
\hline
\end{tabular}

